\title{
EVANGÉLICOS NO CÁRCERE: REPRESENTAÇÃO DE UM PAPEL DESACREDITADO*
}

\author{
Camila Caldeira Nunes Dias \\ Universidade de São Paulo
}

Resumo: Este artigo pretende abordar a questão da religiosidade evangélica dentro da prisão observando, de um lado, as transformações produzidas em decorrência da conversão religiosa e, de outro, compreender o lugar e a posição que este grupo ocupa no sistema social prisional. Para isso, analisamos as relaçôes estabelecidas entre os evangélicos e a massa carcerária, marcada por tensōes e ambigüidades, que conformam e definem as características deste grupo religioso dentro da prisão: a ilegitimidade e o descrédito. As interações entre evangélicos e massa carcerária estão constantemente ameaçadas de ruptura, o que torna essa realidade social extremamente precária.

Palavras-chave: conversão, evangélicos, prisão, tensão.

Keywords: conversion, evangelicals, prision, tension.

O objetivo deste texto é discutir a religiosidade evangélica dentro da prisão, a partir de dois pontos de referência: de um lado, considerando esse fenômeno a partir do grupo religioso, apontando as transformações ocorridas no universo discursivo dos indivíduos em decorrência da conversão religiosa. Num segundo momento, porém, introduziremos considerações que dizem respeito ao lugar ocupado pelos evangélicos neste peculiar sistema so-

\footnotetext{
Uma versão deste texto foi apresentada, com o título Prática Religiosa na Prisão: Tensões e Ambigüidades, no XXV Congresso da Associação Latino-Americana de Sociologia (Alas), realizado em Porto Alegre, entre os dias 22 e 26 de agosto de 2005.

${ }^{* *}$ Mestranda em Sociologia.
} 
cial que é o universo prisional. Nesse sentido, aparecerão inúmeras ambigüidades, tensões e conflitos subjacentes à pertença evangélica que, se não invalidam as proposições apresentadas na primeira parte do trabalho, delineiam uma análise mais complexa do fenômeno, superando a narrativa produzida pelos conversos e contextualizando as atividades evangélicas na dinâmica das relações sociais estabelecidas na prisão, marcadas pela precariedade, característica fundamental desse universo social.

As discussões aqui propostas estão baseadas em pesquisa realizada na Penitenciária I de São Vicente, litoral de São Paulo, e Penitenciária do Estado de São Paulo, localizada no bairro Carandiru, na capital paulista, durante os anos de 2003 e 2004.

A escolha dos evangélicos enquanto foco para nossas análises não se deu por acaso, pois estes se constituem num grupo à parte dos demais presos, destacando-se tanto por sua aparência quanto por sua conduta, radicalmente diferente daquela adotada pela massa carcerária. Essas diferenças, assim como as tensões e os conflitos que envolvem sua pertença religiosa, aparecem como características próprias desse grupo religioso.

\section{PARTICULARIDADES NO MUNDO SOCIAL DA SOCIEDADE DOS CATIVOS}

Para compreender o significado de práticas que ocorrem no espaço prisional é preciso, antes de tudo, atentar para as particularidades desse sistema social. De acordo com Sykes (1974) o sistema social constituído no interior do espaço prisional é marcado pela especificidade das normas e valores que presidem as relações aí estabelecidas e deve ser entendido como uma sociedade dentro da sociedade mais ampla.

A identidade assumida por um indivíduo está diretamente associada, conforme aponta Goffman (2002), às disposições institucionais que definem aquilo que se espera que um indivíduo seja, a partir do estabelecimento de certos padrões e características constitutivas do papel que o mesmo deverá representar, a fim de corroborar a posição e o lugar que determinada instituição social lhe destina. Dessa forma, para compreender as identidades consti- 
tuídas numa instituição tal como a prisão, é preciso tentar entender quais papéis sociais estão disponíveis nesse estabelecimento, tendo em vista os padrôes vigentes nas relações sociais aí estabelecidas.

O sistema social prisional não admite uma variedade muito grande em termos das identidades possíveis de serem assumidas pelos presos. Esse sistema social é constituído por dois mundos, antagônicos e opostos: o mundo do trabalho e o mundo do crime. ${ }^{1}$

Ao mundo do trabalho estão associadas normas de conduta, valores e comportamentos que regulam nossa vida na sociedade mais ampla. Os presos que se identificam com esse mundo não se consideram como pertencentes ao mundo do crime. Ao contrário, valorizam o trabalho, a família, a educação e procuram traçar planos para o momento de retorno à sociedade, fora do âmbito da ilegalidade.

Contudo, os indivíduos que perseguem esses valores dentro da prisão devem se submeter ao sistema normativo mais amplo dessa sociedade, que é o código delinqüente. ${ }^{2}$ Esse conjunto de regras e valores está baseado, principalmente, na lealdade aos seus pares - e daí a regra máxima que é não delatar o companheiro - e nas atividades ligadas ao comércio e uso de drogas ilegais dentro da cadeia. Estes dois pilares da sociabilidade do mundo do crime, e que norteiam, em conjunção com as normas oficiais da administração prisional, as relações estabelecidas no universo carcerário, estão pautados em valores ligados a uma concepção de dignidade, coragem e honra que devem ser preservados a qualquer custo.

Esse código normativo deve ser seguido à risca por aqueles indivíduos que se encontram nesse particular sistema social. A desobediência ou a infração a alguma dessas regras ou leis acarreta sanções, que vão desde agressões físicas até a morte do transgressor.

Com o crime organizado se incrustando e deitando suas raízes no universo carcerário, esse sistema normativo e de valores vem adquirindo uma

1 Essa oposição encontra-se em Ramalho (2002).

2 Para uma descrição do código delinqüente, ver Sá (1996). 
forma mais perversa ainda, sendo os chefes ou líderes das facções criminosas organizadas os responsáveis pelo funcionamento do sistema social prisional, pela observância do cumprimento desse código e pela imposição das sanções aos transgressores. Essas lideranças estão presentes em todas as unidades prisionais e são chamadas de "piloto".

Assim, para compreender o sentido da prática evangélica no interior do cárcere é imperativo que ela seja considerada no contexto onde se realiza, ou seja, tendo em vista o padrão de relações sociais vigentes na prisão, regulado por valores e normas específicas a esse universo.

\section{CONVERSÃO: PASSAGEM DE UM MUNDO A OUTRO}

A conversão religiosa será tratada enquanto um processo de transformação no universo discursivo do indivíduo, que engloba uma mudança de valores, crenças, comportamento e na forma de interpretar os acontecimentos (Snow; Machalek, 1984).

Se há a coexistência de dois universos - o do crime e o do trabalho dentro da prisão, a conversão religiosa se constitui enquanto processo que promove uma troca de mundos (Berger; Luckmann, 2000), que envolve o abandono das práticas e dos valores que compõe o que chamamos mundo do crime, e a adoção das normas de conduta, regras morais e valores que conformam o mundo do trabalho.

O discurso religioso ressignifica a trajetória biográfica do indivíduo, dando novas cores e novos sentidos ao seu passado, presente e futuro; o trabalho e, junto com ele, a educação passam a ser vistos como vias de retorno à legitimidade social; e, por fim, os laços familiares - em conjunto com o vínculo mantido com o grupo religioso - são alçados à categoria de ponto de apoio fundamental para a manutenção dessa identidade baseada nos preceitos evangélicos. 
RECONSTRUÇÃO DA TRAJETÓRIA BIOGRÁFICA A PARTIR DO ARCABOUÇO DISCURSIVO DA DOUTRINA

O preso que se converte ao pentecostalismo passa a compreender o seu passado no crime como uma transgressão às leis divinas, percebendo, dessa forma, o seu presente - o tempo passado na prisão - como um momento de castigo e, ao mesmo tempo, de aprendizado.

Reconhecendo os seus erros passados e a necessidade da prisão para o reconhecimento destes, o indivíduo dá sentido a essa vida pretérita marcada pela violência e, sobretudo, dota de significado esse tempo presente, dramático e carente de sentido.

O futuro para esses indivíduos é identificado com a vida aqui e agora, ou, mais precisamente, com o momento de retorno à sociedade. É esse futuro que mais atemoriza e angustia a maioria daqueles que se encontram na prisão. O discurso religioso lhes permite traçar planos, delinear seu futuro, superando o sentimento de descontinuidade no tempo, que caracteriza a população carcerária e, muitas vezes, impede que esses indivíduos consigam fazer um planejamento que envolva sua vida após o cumprimento da pena.

A conversão religiosa permite, em suma, uma reinterpretação biográfica, dentro do aparelho legitimador da nova realidade proposta pelo discurso religioso. Esse aparelho legitimador promove a harmonização do passado, do presente e do futuro do indivíduo, descartando alguns traços e eventos, ressignificando outros, produzindo, dessa forma, um conjunto de acontecimentos que são plenamente significativos. Afasta-se, assim, o caos e a anomia, e restaura-se a ordem e o sentido da vida do converso. ${ }^{3}$

TRABalHo E EDUCAÇÃO: VIA DE RETORNO À LEGITIMIDADE SOCIAL

Para justificar o abandono das práticas ilícitas ou criminosas em troca de um trabalho que exige pouca ou nenhuma qualificação, e cujos ganhos são,

3 Ver Berger e Luckmann (2000), Berger (1985) e Snow e Machalek (1984). 
na grande maioria das vezes, muito menores do que os lucros obtidos ilegalmente, os evangélicos mobilizam uma argumentação que aponta uma supervalorização do trabalho em si mesmo, independentemente do retorno financeiro.

Esses indivíduos se dizem conformados a executar um trabalho que ofereça pouco prestígio social, e os desejos de prosperidade financeira são interpretados como ganância e, portanto, parte do universo que o indivíduo deixa para trás.

A educação é valorizada enquanto instrumento de auxílio na promoção da qualificação profissional, para abrir oportunidades de reinserção social. A valorização da educação universal, de aquisição de cultura per se, inexiste para esses indivíduos imersos em problemas e questões que exigem soluçóes imediatas e urgentes.

FAMÍLIA E GRUPO RELIGIOSO: SUSTENTÁCULOS DA ORDEM MORAL

Os presos evangélicos buscam resgatar os laços que, na maioria das vezes, se encontravam estremecidos ou mesmo rompidos com sua família, e vêem o grupo familiar como uma bóia onde esperam poder se agarrar para ter condições de abandonar de vez o mundo do crime.

O aprofundamento da vida desses indivíduos no mundo do crime é marcado, na maioria das vezes, pelo seu afastamento da família, o que caracteriza o momento de rompimento dos vínculos sociais mais importantes. Vínculos estes essenciais para a constituição do homem enquanto ser moral, e que nos torna parte do todo social. ${ }^{4}$

Muitas vezes, contudo, o preso provém de uma família tão desestruturada, cujos laços se esgarçaram a tal ponto, que a aproximação torna-se impossível. Nesses casos a igreja propõe ao indivíduo constituir-se como a substituta da família enquanto sustentáculo de sua consciência social, base para manutenção da ordem moral e ética pela qual o indivíduo deve orientar suas açóes.

${ }^{4}$ Ver Durkheim (2000). 
O grupo religioso é apresentado ao indivíduo, nesses casos, como o refúgio solidário e moralmente forte, que assegura a manutenção dessa estrutura de plausibilidade fornecida pelo discurso evangélico. É no grupo religioso que esse indivíduo encontra as bases sobre as quais lhe é possível sustentar essa identidade recém-assumida, que tem na doutrina pentecostal seus elementos constituintes. Fornece ao preso, em suma, a possibilidade de estabelecer laços sociais que o vincule novamente à sociedade e que dê sentido à sua pertença social.

\section{GRUPO RELIGIOSO: INTERAÇÃO INTENSA E ISOLAMENTO DA MASSA CARCERÁRIA}

É o grupo religioso que fornece a estrutura de plausibilidade necessária para o indivíduo conservar sua identidade evangélica. Isso significa, acima de tudo, promover uma interação intensa do grupo religioso, desenvolvendo atividades que ocupem todo o tempo disponível do indivíduo e, ao mesmo tempo, desqualificar todas as identidades que venham a competir com aquela proposta pela religião.

Especialmente nas prisões, onde há um número elevado de pessoas convivendo num mesmo local, a manutenção da identidade religiosa exige uma verdadeira blindagem dos conversos, que conta inclusive com o seu isolamento físico, traduzidos na existência de celas exclusivas para os crentes. Nestas últimas, o indivíduo é obrigado a seguir uma série de preceitos, regras e normas que definem e caracterizam o estereótipo pentecostal, cuja base é a condução de uma vida santificada.

Segundo os presos responsáveis por essas igrejas, o número elevado de atividades religiosas dentro da cadeia é fundamental para a manutenção do converso dentro das normas e das regras de conduta impostas pela religião, pois, segundo eles, se o preso dispuser de tempo livre ele ficará suscetível às influências perniciosas do ambiente prisional.

Além disso, é importante salientar que, se na Penitenciária I de São Vicente a única denominação existente era a Assembléia de Deus, na Penitenciária do Estado, além desta, entrevistamos presos pertencentes às seguintes igrejas: 
Deus é Amor, Universal do Reino de Deus, Missão Evangélica Mensagem de Cristo, Nazareno, Adventista do Sétimo Dia e Testemunhas de Jeová. Surpreendentemente, no entanto, todas as observações feitas até este momento, assim como aquelas que seguirão, são válidas indistintamente para os fiéis de todas as igrejas apontadas acima.

Assim, a despeito das diferenças teológicas, rituais e doutrinárias entre essas igrejas, dentro do cárcere elas constituem-se enquanto um todo uniforme e homogêneo. ${ }^{5}$

Conforme já apontamos, em complemento com a ampla gama de atividades religiosas que o crente na cadeia é obrigado a se envolver, há um repertório não menos amplo de atividades que o mesmo é proibido de realizar. Aqui se instala um dos motivos mais importantes para os conflitos e as tensões estabelecidas entre os evangélicos.

Segundo os líderes das igrejas dentro da prisão, uma de suas incumbências mais importantes, e que lhes dá mais trabalho, é justamente a necessidade de vigiar seu rebanho o tempo todo, a fim de ter certeza de que os mesmos estão cumprindo as normas da igreja. Segundo esses presos, a grande maioria dos conversos resiste a acatar tais ordens, e, nessas ocasióes, instaura-se um problema, cuja solução ultrapassa o âmbito de influência dos pastores ou presos evangélicos.

Mas, para explicar melhor essa questão, introduziremos mais informações nesta análise. A partir de agora, apresentaremos alguns elementos que dizem respeito não mais à organização e às relações internas entre os evangélicos, mas às relações estabelecidas entre estes e a massa carcerária. Sem dúvida, residem nesse relacionamento muitas das explicaçôes que caracterizam e definem a posição real dos evangélicos no sistema social prisional. Dada a especificidade desse mundo social, não podemos alcançar a compreensão exata dessas atividades simplesmente transportando o arcabouço teórico que utilizamos para interpretar os fenômenos religiosos que ocorrem na sociedade mais ampla.

5 Para uma discussão das diferenças existentes entre as várias vertentes pentecostais, ver Mariano (1999). 


\section{IGREJA COMO REFÚGIO E A BÍBLIA COMO ESCONDERIJO}

Há uma desconfiança constante pairando sobre os presos evangélicos, ligada a uma suposta ausência de sinceridade na sua devoção religiosa. Há uma unanimidade quanto a essa questão, por mais estranho que pareça, mesmo quando são considerados os discursos dos próprios religiosos - sempre tomando o cuidado de enfatizar, obviamente, que não se tratava do caso daquele que estava falando, mas sim de outros membros da igreja.

"Esconder-se atrás da Bíblia” é um jargão freqüentemente utilizado para se referir às pessoas que teriam se convertido por razôes alheias àquelas propriamente religiosas.

Dizer que alguém está se escondendo atrás da Bíblia significa dizer que essa pessoa está fingindo ser crente para fugir de acertos de contas com a massa carcerária. Conforme já expusemos antes, nas normas que regulam a relações sociais entre os membros da sociedade dos cativos, não existe possibilidade de perdão - tudo tem seu preço. Dessa forma, ao quebrar uma regra o preso permanece numa situação extremamente delicada, sujeito a inumeráveis penas, que vão desde humilhações e agressões à perda da vida.

Uma das alternativas para resolver essa questão é a conversão religiosa, ou, nas palavras dos presos "correr para a igreja". Uma vez tendo se convertido ao evangelho o preso permanece apartado da massa carcerária, deixa de fazer parte do mundo do crime - e daí as inumeráveis atividades religiosas às quais deve se submeter e as muitas outras que lhe são proibidas.

Esse indivíduo é, por assim dizer, expulso do mundo do crime, a partir do momento em que infringe uma de suas regras. Uma vez expulso é exigido do mesmo que uma outra identidade seja assumida. $\mathrm{O}$ infrator das leis do crime não pode mais ser "malandro", não faz mais parte desse mundo; sabe que é só uma questão de tempo e de oportunidade para que seus inimigos promovam o acerto de contas, tão comum nas relações sociais estabelecidas na prisão.

A identidade de evangélico é, dessa forma, extremamente desacreditada pelos demais. $\mathrm{O}$ evangélico deve se manter o tempo todo vigilante no seu papel de crente, tomando cuidado para que nenhuma atitude esteja em desacordo com essa identidade. 
Assim, sendo a prisão uma instituição na qual ocorre o que Goffman (2001) denomina “despojamento do papel”, isto é, a impossibilidade de representarmos diversos papéis na nossa vida cotidiana, conforme fazemos na sociedade mais ampla, a vida social nesse estabelecimento é marcada pela precariedade, estando os encontros sociais que aí ocorrem sempre sujeitos à ruptura de sentido.

Assumindo, pois, a identidade de crente, o indivíduo deve representar esse papel o tempo todo. Deve, para isso, esconder informações ou atributos que possam desacreditá-lo no papel que representa (Goffman, 1988). Ocorre que, na prisão, convive-se com as mesmas pessoas durante muito tempo, sem ter privacidade alguma, e, em decorrência disso, há uma tensão permanente e um conflito constante entre aquilo que os indivíduos tentam mostrar que são e o que transparece nas suas atitudes.

Uma fórmula muito utilizada pelos evangélicos para tornar a sua identidade religiosa mais autêntica, mais acreditada e legítima, é buscar no seu passado a existência de vínculos com a religião evangélica, os quais, na prisão, teriam sido retomados.

Ao voltar ao passado para justificar sua pertença religiosa atual, o indivíduo busca estabelecer uma continuidade na sua biografia que permita dar inteligibilidade à sua situação atual. Busca legitimar sua conversão apelando para uma pretérita ligação com a religião, que teria sido, dessa forma, retomada no momento presente.

A conversão religiosa, conforme vimos anteriormente, significa uma ruptura com o passado, com o mundo do crime. Mas, para torná-la legítima, muitas vezes é necessário recorrer a esse mesmo passado, ressignificando elementos antes dotados de menor importância, a fim de dar sentido a uma situação que, de outra maneira, careceria de credibilidade.

\section{QUEBRANDO A PERNA DO CRIME, MAS SUBMETIDO AO SEU CONTROLE}

"Quebrar a perna do crime" é uma outra gíria utilizada na cadeia para representar, de um lado, uma certa desilusão da massa carcerária com o ban- 
dido que abandona sua vida no crime, especialmente quando esta está repleta de façanhas, com crimes e/ou fugas espetaculares. Mas aponta, também, para o já aludido descumprimento das regras desse mundo. Assim, a expressão "quebrar a perna do crime" é utilizada para se referir a alguém que deixa de ser "digno" de fazer parte desse universo.

Dessa forma, se já não é mais possível ao indivíduo integrar esse universo que denominamos mundo do crime - composto pela massa carcerária -, destitui-se o mesmo de todos os atributos que conformam a identidade do malandro. ${ }^{6}$

Quando um preso é "expulso" do mundo do crime ele é rebaixado na escala moral que constitui esse universo, e fica impedido de fazer qualquer coisa que lembre aquele mundo que, mais do que ele decide abandonar, ele é obrigado a se afastar. Assim, o preço cobrado pela massa carcerária para deixar o infrator fisicamente intacto é retirar-lhe todo seu valor de malandro, destituindo-o de todos os atributos que faziam dele membro desse universo.

Mais do que os pastores das igrejas que vêm de fora, ou dos presos que são responsáveis pelas igrejas dentro da cadeia, quem realmente determina o que deve ou não ser feito para e pelos evangélicos são os pilotos, os líderes das facções organizadas que mantêm o controle da prisão. Ou seja, não são os evangélicos, baseados na doutrina de suas igrejas, que decidem o que devem fazer e do que devem se afastar para garantir a permanência e a credibilidade de sua identidade religiosa. Ao contrário. Tudo aquilo que lhes é permitido, proibido ou imposto o é por ordem da massa carcerária. Faz sentido, desta forma, a homogeneidade, apontada anteriormente, das diversas denominações evangélicas dentro da prisão, a despeito das diferenças significativas que algumas delas apresentam, principalmente em termos das exigências comportamentais de seus fiéis, na sociedade mais ampla.

Para garantir que aqueles que deixaram de ser dignos de pertencerem ao mundo do crime estão, de fato, afastados deste, a massa carcerária - assim

6 Para uma explanação das virtudes e do comportamento esperados do "malandro", ver Ramalho (2002) e Sá (1996). 
como os funcionários - exercem uma vigilância contínua, ininterrupta e sistemática sobre os evangélicos, além de promoverem armadilhas e provocaçôes que tentam fazer com que os crentes tenham atitudes que não correspondam àquelas associadas ao estereótipo pentecostal e possam, dessa forma, serem desacreditados.

Mais do que uma opção religiosa, a pertença evangélica na cadeia aparece como decorrência de algumas situaçóes criadas no cotidiano prisional, que por vários motivos tenham tornado impossível o convívio com os demais. Uma vez tendo feito essa "escolha", o indivíduo é obrigado a seguir as rígidas normas comportamentais da igreja, sob pena de ser obrigado a pedir seguro, ${ }^{7}$ transferência para outra cadeia ou ter sua vida colocada em risco.

$\mathrm{O}$ mundo do crime não perdoa as infrações às suas normas. $\mathrm{O}$ fato do indivíduo se tornar evangélico o descredencia de imediato desse mundo; ele não pode mais, portanto, ser cobrado pelas faltas cometidas anteriormente, mas deixa de ter o respeito dos demais.

No esquema interpretativo de Goffman (2002), quando um grupo se encontra com outro com o objetivo de interação, cada um tende a sustentar aquilo que afirma ser - no caso ao qual nos referimos, tem-se o crente e o malandro - e cada grupo tende a suprimir definiçóes de si mesmo e do outro que possam desacreditar os papéis desempenhados na interação. No caso da relação entre presos evangélicos e os demais membros da massa carcerária, ocorre justamente o oposto, já que os últimos se esforçam para desacreditar os primeiros.

Desta feita, ser crente na cadeia significa estar sempre na berlinda, sujeito ao descrédito por um deslize qualquer, por uma palavra ou um gesto. É a expressão mais acabada de uma identidade mutilada na possibilidade de representar papéis diversos ao religioso. É a expressão da total perda da autono-

\footnotetext{
7 "Pedir seguro" significa solicitar à administração prisional a transferência para uma cela localizada em lugar não acessível à massa carcerária, na qual o indivíduo permanece todo o tempo - isolado -, exatamente para preservar sua integridade física, preservando-se do contato com os demais presos.
} 
mia e da personalidade. É reduzido a alguém que, a fim de manter sua integridade física, é destituído de sua integridade moral.

Uma questão importante e que deve ser ressaltada é que, mais do que uma situação que pode ser reduzida a casos individuais, isso que estamos apontando define o lugar do crente dentro desse sistema social que é a prisão. Menos do que se referir ao caso de um ou outro preso, que, comprovadamente, tenha descumprido as normas da massa carcerária, essa situação de descrédito é a definição mesma do lugar ocupado pelos evangélicos - enquanto grupo. Ou seja, longe de constituírem uma exceção no padrão de relação social vigente, esse controle externo e a contínua desconfiança estruturam a relação entre evangélicos e massa carcerária, produzindo uma contínua instabilidade e tensão nas suas interaçóes.

\section{CONCLUSÃO}

Os poucos estudos que tratam das atividades religiosas no contexto prisional tendem a focar suas análises na eficácia destas no processo de ressocialização do preso. Nesse sentido, temos basicamente duas posições opostas: de um lado a defesa da religião enquanto elemento moralizador por excelência, capaz, portanto, de auxiliar na promoção da recuperação do indivíduo preso $^{8}$ e, de outro, argumentos que indicam um aproveitamento utilitário da religião pelos indivíduos encarcerados, na medida em que estes obteriam benefícios - materiais e/ou simbólicos - em decorrência de uma supostamente fingida - conversão religiosa. ${ }^{9}$

Este trabalho aborda o tema de uma perspectiva diferente. Primeiramente, diferencia-se da abordagem instrumental por não entender as trans-

${ }^{8}$ Oliveira (1978) e Beristain (2000) são ardorosos defensores dessa posição.

9 O núcleo da análise de Scheliga (2000) sobre a prática religiosa evangélica dentro da prisão é precisamente a transformação positiva da imagem do converso diante da administração prisional e de outros presos. Soares e Ilgenfritz (2002, p. 38), ao estudarem prisões femininas no Rio de Janeiro, chamaram a atenção para a existência de algumas celas destinadas às presas evangélicas, e apontaram essa separação como benefício obtido pelas mesmas, a partir da conversão religiosa. 
formações ocorridas após a conversão religiosa em termos de obtenção de benefícios. Acredito ter deixado claro em que medida é considerada infundada a idéia de que a adesão ao pentecostalismo promove uma transformação positiva na imagem do preso.

Ao contrário. Diante da administração prisional as práticas religiosas são vistas simplesmente como funcionais, já que seus integrantes, em geral, dão menos trabalho, em termos disciplinares, para os funcionários dessas instituições. Contudo, não há qualquer tipo de vantagem ou benefício concedido a presos unicamente por pertencerem à igreja.

Em relação à massa carcerária essa assertiva é ainda mais falsa, já que, conforme apontamos, os evangélicos são considerados indignos de pertencerem ao mundo do crime. Nesse sentido, inverte-se totalmente a questão e os crentes, ao contrário dos atributos que definem para si mesmos no momento das entrevistas, são indivíduos sem nenhum crédito, sobre quem paira uma desconfiança absoluta e um preconceito enorme.

De outro lado, este trabalho não corrobora todo entusiasmo que vê na religião elemento importante no processo de ressocialização. Se não podemos negar que a conversão religiosa pode operar ressignificações e transformações no repertório de identidades dos indivíduos, diante de tudo o que foi exposto, torna-se muito difícil pensar a questão da possibilidade ou não de ressocialização através da adesão religiosa - deve-se antes perguntar que tipo de sistema social é este onde toda e qualquer ação é vista com desconfiança e onde os mais recônditos comportamentos são vigiados e trazidos à exposição pública; onde as autoridades legítimas não interferem, não arbitram, ao contrário, fazem vistas grossas à opressão, à dominação de alguns grupos, a fim de manter a "paz" nas cadeias, mesmo que o custo dessa "paz" seja a permanência e o recrudescimento da arbitrariedade e do autoritarismo.

Não se está aqui a afirmar que a religião é tão-somente um instrumento de opressão e de punição nas mãos da massa carcerária a fim de castigar os infratores das suas leis. Mas estamos certos, no entanto, de que ela está longe de se constituir como elemento sinalizador de qualquer processo de ressocialização - ela traz, embutidos em si, outros significados.

Num mundo social onde as regras e normas são arbitrariamente impostas por grupos organizados e mantidas a partir do estabelecimento das rela- 
ções sociais entre indivíduos confinados por anos a fio, onde a infração a estas é punida com a maior severidade possível, descortinar possibilidades de sobrevivência - física e psicológica - torna-se uma das mais importantes tarefas a serem desempenhadas. E é nessa chave que a religiosidade evangélica deve ser entendida, ou seja, como parte integrante e importante para a manutenção do funcionamento desse sistema de relações sociais vigentes no universo prisional.

Desnecessário dizer também que, independentemente das motivações reais de cada um ao converter-se ao pentecostalismo, o fato é que recai sobre esse grupo a falta de credibilidade apontada antes. Sociologicamente é essa situação que importa, muito mais do que as inclinações individuais. Assim, a questão dos motivos subjetivos - a falsidade ou sinceridade - para a conversão religiosa não foi tratada aqui, mas sim o fato fundamental que define o evangélico dentro da prisão. Ou seja, ao se declarar crente, o preso ocupará uma determinada posição dentro da cadeia - marcada pelo descrédito - e o papel de religioso será posto a prova todo o tempo, devendo ser reafirmado permanentemente nas interações estabelecidas com os demais membros desse sistema social.

Mais do que qualquer outra, a realidade social criada e recriada numa instituição como a prisão é frágil e precária, as representações aí desempenhadas devem ser mantidas o tempo todo, mediante a mesma audiência, o que sem dúvida a torna mais tensa e mais sujeita à ruptura. Representar o papel de crente nesse sistema social significa conviver rotineiramente com ataques à sua representação e com tentativas de desacreditar e desestabilizar a sua identidade.

Castro (1991, p. 57) chama a atenção para o fato de que, se são bem conhecidas as formas mais diretas de violência, tais como as torturas, os maustratos e a precariedade das condiçôes de vida e trabalho, menos conhecidas são aquelas mais sutis, "constitutivas mesmo da rede de relações sociais que atravessa sujeitos posicionados de modo diferente na estrutura social da prisão". Nossa sugestão é que ser crente dentro da cadeia faz parte dessas formas, sutis, de violência, à qual estão sujeitos aqueles que ocupam o último degrau na hierarquia social da prisão. 


\section{REFERENNCIAS}

BERGER, Peter. $O$ dossel sagrado: elementos para uma teoria sociológica da religião. São Paulo: Paulus, 1985.

BERGER, P. L.; LUCKMANN, T. A construção social da realidade. Petrópolis: Vozes, 2000.

BERISTAIN, Antonio. Nova criminologia à luz do direito e da vitimologia. Brasília: Editora Unb, 2000.

CASTRO, M. M. P.de. Ciranda do medo: controle e dominação no cotidiano da prisão. Revista USP, São Paulo, n. 9-1, p. 57-64, 1991.

DURKHEIM, E. As formas elementares da vida religiosa. São Paulo: Martins Fontes, 2000.

GOFFMAN, E. Estigma: notas sobre a manipulação da identidade deteriorada. 4. ed. Rio de Janeiro: LTC, 1988.

. Manicômios, prisões e conventos. São Paulo: Perspectiva, 2001. . A representação do eu na vida cotidiana. Petrópolis: Vozes, 2002.

MARIANO, R. Neopentecostais: sociologia do novo pentecostalismo no Brasil. São Paulo: Loyola, 1999.

OLIVEIRA, Marina M. C. de. A religião nos presídios. São Paulo: Cortez \& Moraes, 1978.

RAMALHO, J. R. O mundo do crime: a ordem pelo avesso. São Paulo: IBCCRIM, 2002.

SÁ, Geraldo R. de. A prisão dos excluídos: origens e reflexões sobre a pena privativa de liberdade. Rio de Janeiro: Diadorim, 1996.

SCHELIGA, Eva L. "E me visitastes quando estive preso": sobre a conversão religiosa em unidades penais de segurança máxima. Dissertação (Mestrado em Antropologia Social)-PPGAS, Universidade Federal de Santa Catarina, Florianópolis, 2000. 
SNOW, D. A.; MACHALEK, R. The sociology of conversion. Annual Review of Sociology, n. 10, p. 167-190, 1984.

SOARES, B.; ILGENFRITZ, I. Prisioneiras: vida e violência atrás das grades. Rio de Janeiro: Garamond, 2002.

SYKES, Gresham M. The society of captives: a study of a maximum security prison. Princeton: Princeton University Press, 1974. 